\title{
LA ALTERACIÓN DE LOS SOPORTES: A VECES CUBIERTO POR LAS AGUAS DE CARLOS COCIÑA
}

\author{
Pablo Apablaza \\ Universidad Diego Portales \\ Santiago, Chile \\ pmapablaza@gmail.com \\ RESUMEN / ABSTRACT
}

En este artículo pretendo explorar los soportes de publicación del poemario A veces cubierto por las aguas de Carlos Cociña. Esta obra se publica el año 2003 en el sitio web Poesía Cero. Luego, en 2013 aparece incluido en la antología El margen de la propia vida, impreso en páginas sueltas dentro de un sobre; y, finalmente, en 2015, se presenta en una lectura pública y performática junto a la Orquesta de Poetas. Del recorrido digital al impreso y del impreso a la lectura, me interesa analizar el carácter aleatorio de $A$ veces cubierto por las aguas, considerando los procedimientos escriturales de potencialidad y restricción esbozados por el grupo Oulipo. En definitiva, estos recursos establecen un vínculo con la poética de trabajo de Cociña y la desmaterialización de los soportes de publicación (página web, libro impreso y performance).

PALABRAS ClaVE: aleatoriedad, soportes de publicación, poesía digital.

THE ALTERATION OF MEDIA:

A VECES CUBIERTO POR LAS AGUAS BY CARLOS COCIÑA

In this article I intend to explore the publication media of the poem A veces cubierto por las aguas by Carlos Cociña. This work was published in 2003 on the Poesía Cero website. In 2013, it was included in the anthology El margen de la propia vida, printed on single pages inside an envelope, and, in 2015, it was presented along with Orchestra of Poets, in the context of a public and performative reading. From digital to printed and from print to reading, I am interested in analyzing the random nature of A veces cubierto por las aguas, considering the scriptural procedures of potentiality and restriction outlined by the Oulipo group. In short, 
these resources establish a link with the poetics of Cociña's work and the dematerialization of the publication supports (web page, printed book, and performance).

KEYWords: Randomness, Publication Media, Digital Poetry.

Recepción: 31/03/2020

Aprobación: 14/11/2020

La presentación es un problema porque puede convertirse fácilmente en una forma en sí misma,

y esto puede inducir a un error.

Siempre optaré por el formato más neutro, que no dificulte la información o la distorsione.

IAN BURN

La maldita circunstancia del agua por todas partes me obliga a sentarme en el café. Virgilio Piñera, La isla en peso

"Pero casi siempre las aguas forman un curso, cuyo origen está en cualquier momento de las cosas", dice uno de los fragmentos de $A$ veces cubierto por las aguas (2003), de Carlos Cociña, conjunto de poemas para ser leído en la pantalla de un computador mediante un motor de búsqueda aleatorio creado para el sitio web Poesía Cero ${ }^{1}$. El fragmento que cito anuncia el despliegue de distintos estados del agua, estados contenidos en tres soportes: uno virtual, en Internet; otro físico, impreso en páginas sueltas dentro de un sobre y publicado en la antología El margen de la propia vida (2013); y otro presentado en una lectura performática junto a la Orquesta de $\operatorname{Poetas}^{2}$ (2015).

$1 \quad$ https://www.poesiacero.cl/.

2 Orquesta de Poetas es un "proyecto de experimentación poético-musical que busca fusionar ambas disciplinas en un repertorio que se inscribe como propuesta en la tradición de las vanguardias de música y de poesía sonora, donde también concurren lo escénico y lo visual, conformando una experiencia estética compleja y pulsional, que se propone trabajar en la frontera de la música y la poesía, sin llegar a la canción, ni tampoco a la poesía sonora pura u obra indescifrable. La Orquesta de Poetas nació a comienzos de 2011, a partir de la reunión de cuatro escritores y músicos interesados en estudiar y experimentar en el cruce de ambos campos. En este proceso, han desarrollado distintos procedimientos y técnicas, desde la superposición de voces a capella e improvisaciones vocales no verbales, hasta el uso de loops 
A medida que sucede la lectura de esta obra, hay una tensión en los modos de publicación y circulación que afecta materialmente los poemas. No hay un cambio de sustancia en los textos de Cociña, sino que estos aparecen en otros contenedores, en otros estados. Sin duda, como aprecia Mario Montalbetti, el lenguaje modifica su estado físico a causa del poema: "el lenguaje, así como el agua, tiene estados" (157). Es decir, el poema sería una alteración física del lenguaje y, por qué no, de los soportes que lo contienen.

En una entrevista, Carlos Cociña se refiere a la importancia de este trasvasije del soporte material:

Pero quiero hacer una salvedad: no creo que necesariamente un libro -como yo los entiendo- esté terminado cuando se imprime en soporte papel, creo que también se puede hacer en otro soporte, y que algún libro podría estar definitivo en publicación en Internet u otro soporte ("Desde el tímpano hacia dentro" 1).

Las decisiones de Cociña son claras. Opta por entender los libros como proyectos y no como recopilaciones, y por un trabajo en secuencia con ciertas regularidades, atendiendo a este asunto del soporte, a su sentido que se inicia en el lenguaje digital, y a lo gráfico, incluyendo los métodos de impresión y circulación. Y es que, como aprecia Leslie Howsam, los libros no son categorías sino procesos: acontecen en la lectura, se reproducen, se componen o diseminan y resultan significativos (5). Por eso mismo, en este ensayo exploro los soportes en que se publicó $A$ veces cubierto por las aguas. Me interesa la lectura del carácter aleatorio del recorrido digital al performático, considerando los procedimientos escriturales de potencialidad y restricción que elaboró el grupo Oulipo. Creo que estos modos de enfrentar la publicación -página web, libro impreso y performance- establecen un vínculo con la desmaterialización de los soportes y la poética de trabajo de Cociña.

Uno de los problemas que afronta esta escritura es la potencialidad literaria. En ese sentido, hay una cercanía con lo propuesto por el grupo Oulipo ${ }^{3}$, cuyo

y efectos digitales del ámbito de los djs y la música electrónica, en relación con lenguajes musicales que abarcan tanto la música latinoamericana como el jazz o el rock. Este interés se ha expandido, en sus presentaciones en vivo, a la utilización de proyecciones visuales y recursos performáticos" ("La Orquesta” párr. 1-2).

Jean Lescure, en "Breve historia del Oulipo", señala que en 1960 François Le Lionnais y Raymond Queneau fundaron un grupo de investigaciones en literatura experimental. 
objetivo es explorar los recursos de la lengua desde restricciones literarias y conceptos matemáticos. Este trabajo experimental se basa en un programa que busca las potencialidades de la literatura, a través de dos misiones: la primera consiste en "inventar estructuras, formas o nuevos desafíos que permitan la producción de obras originales" (Bénabeu 11) por medio de conceptos matemáticos y la utilización de recursos combinatorios ${ }^{4}$; la segunda tarea se funda en el rastreo de estructuras, formas y restricciones en obras literarias antiguas.

El programa oulipiano se basa en el principio de la restricción que despliega la idea potencial de la literatura y considera el aspecto material del lenguaje, al que ve como objeto en sí. El papel de la restricción, según Bénabeu, sería "obligar al sistema del lenguaje a salir de su funcionamiento rutinario" (13). En vez de bloquear la creatividad, estas formas -que podrían considerarse como "no-creativas", siguiendo al poeta experimental Kenneth Goldsmith- la activan y la estimulan. De ahí se entiende que el propio Cociña destaque en una entrevista que "todo trabajo en arte está condicionado" ( $E l$ margen de la propia vida 117) y precise que, cuando se dispone a trabajar, escribe siguiendo "ciertas condicionantes, ciertos límites, porque [su] única posibilidad de romper ciertos límites es tenerlos, si no es el delirio" (ibid.). Es crucial en la obra de Cociña haber dado con estructuras y no es azaroso que adopte una u otra, pues las estructuras determinan ciertos problemas en torno a la creación ${ }^{5}$. Así, cobra importancia el lugar donde se inscriben los

En diciembre de ese año, el grupo adquirió un nombre y pasó de llamarse SLE (reducción de "Sélitex": Seminaire de littérature expérimental) a Oulipo (Ouvroir de littérature potentielle [Taller de literatura potencial]). Lescure indica que Oulipo "pretendía mostrar que las restricciones son tan hermosas, tan generosas, como la literatura misma" (50) y que las investigaciones y los ejercicios del taller tenían que ver con la exploración y las operaciones que trabajan con el lenguaje como objeto concreto, considerando que todo texto literario tiene una cantidad indefinida de significados potenciales.

Un ejemplo de la utilización de recursos combinatorios y matemáticos es Cien mil millones de poemas de Raymond Queneau, una obra que "permite a cualquier persona componer a voluntad cien mil millones de sonetos [...] Es, al fin y al cabo, una especie de máquina de fabricar poemas en número limitado, aunque es verdad que ese número limitado provee lecturas para casi doscientos millones de años" (Cien mil millones 143).

Así lo ve François Le Lionnais, en "La lipo (primer manifiesto)": "Toda obra literaria se construye a partir de una inspiración (al menos es lo que el autor da a entender) que debe acomodarse a una serie de restricciones y procedimientos que se insertan unos en otros como muñecas rusas. Restricciones de vocabulario y de gramática, restricciones vinculadas con las reglas de la novela (división en capítulos, por ejemplo) o de la tragedia clásica (regla de las 
textos. En el caso de $A$ veces cubierto por las aguas y su recorrido hay dos factores experimentales y potenciales en común: lo aleatorio y lo abierto.

Me refiero al carácter aleatorio en la dimensión de los tres soportes. En cada una hay un factor de azar: en la web, donde predomina el motor de búsqueda; en el impreso, donde el factor coincide en lo suelto; y en la performance, cuyo factor temporal y espacial afecta las sonoridades de la acción. En cuanto a lo abierto, pienso en una superficie porosa, no-definitiva: $A$ veces cubierto por las aguas configura un dispositivo posdigital, como plantea Roberto Cruz: un objeto que sucede desde materialidades híbridas, que puede "existir en la combinación o tránsito entre soportes y lenguajes" (párr. 9). Por lo mismo, antes de inmiscuirme en el recorrido digital-impresoperformático, describiré la obra de Cociña.

En las primeras páginas de El margen de la propia vida aparece un texto titulado "Arte poética":

Posiblemente, no hay explicación plausible al hecho de la escritura llamada literaria. Muchos estudios pueden interpretar textos e, incluso, ver los usos verbales, tipográficos y espaciales o de sonidos para plantear hipótesis de cómo se genera sentido. Sin embargo, el acto escritural mismo responde a mecanismos tan diversos como las circunstancias sociológicas y sicológicas del individuo en proceso de escritura. Este hecho lo explicita el escribiente en el mismo texto, y el término de intercambio obedece a impulsos, racionalizados o no, que en este caso tienen un posible origen en la necesidad de crear silencios cuya comunicación ocurre en el tiempo, entendido este como relativo, pero al unísono en la materialidad del cuerpo que se puede expandir y contraer sin más margen que la propia vida (7).

Una primera lectura podría dar con el modo de estas estrategias retóricas, las que parecen preceptivas, ligadas a lo específico de un ars poetica, es decir, a lo que el poeta practica y ve en la poesía, y que fue un ejercicio común de los escritores hispanoamericanos del principio del siglo xx. No es de mi interés señalar esas vías, sino ver, en este texto de entrada, la pregunta por la escritura, por qué esta es como es.

tres unidades), restricciones de la versificación en general, de las formas fijas (como en el caso del soneto), etc.” (Le Lionnais párr. 7). 
La pregunta arrastra la escritura hacia un "escribiente" al que le recae este proceso. No es primera vez que Cociña utiliza la figura del "escribiente" 6 para definir la práctica escritural, también lo hace en la entrevista que cité más arriba -"desde que comencé a escribir y a plantearme ser escritor, escribiente" ("Desde el tímpano hacia dentro" 9)- y pienso en las tareas que confluyen en la autoría de un libro para el siglo XIV:

Hay cuatro formas de hacer un libro. Hay algunos que escriben las palabras de otros sin añadir ni cambiar nada en absoluto, y el que hace esto es un escriba (scriptor). Los hay que escriben palabras de otros y añaden algo, pero los añadidos no son suyos. El que hace esto es un compilador (compilator). Después, están los que escriben tanto palabras de otros como suyas propias, pero predominan las de otros y añaden las suyas como complemento aclaratorio. El que hace esto es un comentador (commentator), más que un autor. Pero quien escribe tanto lo propio como lo que toma de otros, añadiendo las palabras de estos para confirmar las suyas, autor (auctor) (Illich En el viñedo del texto 141).

Ninguna de las categorías propuestas supone una autoría como hoy la entendemos. Allí, como en el proyecto de Cociña, es posible identificar una conciencia con el trabajo de los otros. Se es consciente de una propuesta que no recae en la originalidad. Cociña utiliza el término "escribiente" agenciándolo, para trabajar un proceso temporal y espacial de escritura. Además, la definición que da la Real Academia Española del concepto -"persona que tiene por oficio copiar o poner en limpio escritos ajenos, o escribir lo que se le dicta" (párr. 1)- no me hace sino equipararla a la idea de Plagio del afecto (2009) ${ }^{7}$ $\mathrm{y}$, específicamente, al método del montaje. A propósito, el montaje como

6 Cociña plantea el término agenciándolo. Joan Corominas determina que escribiente es una deriva de la palabra escritura, pero también una forma "catalanizante" (711) con el sentido de escribano. En esa secuencia, escribano (del latín scriba) se define, a menudo como "autor" o "escritor" (ibid.).

Plagio del afecto es un libro que tiene versión digital e impresa. Son 52 "afectos" en la web y 53 en el libro impreso (el último es una página en blanco). Aquí se reproducen fragmentos provenientes de científicos, sociólogos, biólogos, cineastas y escuchas de la calle intervenidas por el autor. El propio Cociña, al hablar de este libro, confiesa: “¿por qué plagio textos no literarios, artículos científicos? Porque pretenden hablar desde la verdad, y sé que eso es mentira" ("Desde el tímpano hacia dentro" 5). 
tal es una configuración de imagen de mundo, que puede venir de la poesía misma. Andrés Claro da cuenta de que el "dispositivo de montaje poético" (47) genera interrupciones, simultaneidades efímeras, proyecta una serie caleidoscópica de representaciones y produce en el poema efectos polivalentes y no intencionales, distanciados.

El "escribiente" se asume en su oficio, el de montajista, con toda la agentividad que implica. De un modo parecido, Juan Luis Martínez ve que en la escritura la participación del autor debe ser mínima: "Para mí, el autor es un lector que lee y traslada con eficiencia ciertos textos que no se han resaltado" (75). El lugar de trabajo del escribiente, al menos en Cociña, es un lugar neutro, donde "escribir consiste en alcanzar, a través de una previa impersonalidad [...] ese punto en el cual sólo el lenguaje actúa, "performa" (Barthes 66). La articulación de un texto, como nota Roland Barthes, representa una multiplicidad, una escritura con procedencias culturales, que dialoga, cuestiona y quien recoge esta construcción, finalmente, es el lector.

Al montar, Cociña propone una acción, percibe cierta imagen de mundo, escribiéndose desde la impersonalidad. Matías Ayala establece algunos procedimientos experimentales de Cociña en la escritura: la neutralidad, la conciencia reflexiva y concentrada en torno a las cosas, la anulación del sujeto, también mediante la especulación teórica y una mirada móvil y minuciosa. Estoy de acuerdo con Ayala cuando señala que el factor fundamental de la obra de Cociña es la impersonalidad (1). Este elemento equidista con la labor del montaje, en el sentido de que es una forma de enfrentar el poema y el despliegue de lo visual, así como la alternancia entre "mirada estricta y referencial con las reflexiones más abstractas y teóricas" (2) junto al método textual, discursivo-analítico y experimental que aparece en $A$ veces cubierto por las aguas. Si los poemas de Cociña buscan anular el sujeto, entonces lo impersonal se da de forma íntegra, y aquí se puede pensar como referente a Gonzalo Millán y la óptica de La ciudad (1979), la objetividad del lenguaje, "una máquina hecha de palabras" (Millán 57), y la neutralidad. Creo que la lectura de Millán entabla la tensión que mostraba la poesía concreta y visual de los sesenta, la búsqueda de "la página como unidad que reemplaza al verso" (44), la búsqueda de la objetividad y del "menor lirismo posible" (Millán cit. en Ayala 79); una poesía mínima, "de cero grado poético" (ibid.), la relación del escribir como objeto y medio, además del libro y su soporte; en rigor, antecedentes que Cociña explota en el poema.

Para finalizar esta introducción, creo que el trayecto de ir de lo digital hacia lo performático sugiere una reflexión sobre la desmaterialización del 
poema. Fuera de la página y del verso, A veces cubierto por las aguas, con su potencialidad aleatoria, se inmiscuye dentro de un estilo impersonal y dentro de un marco experimental frente a la obra-como Lucy R. Lippard describe para el conceptualismo de finales de los sesenta y principios del setenta (80)- que pone el foco en los procesos mentales y en la ejecución distanciada. No es que Cociña manifieste un desinterés por la evolución de los materiales del poema, sino por lo que constituyen otros programas que no enfatizan la impersonalidad, centrados quizá en otro tipo de temples, exacerbados, de filiación romántica. El foco que intento pensar radica en la materialidad de los soportes, en la importancia que tendría el diseño de la página web, el sobre, la performance, y analizar qué ocurre mientras el procedimiento de la "maquinita de azar" (Cociña, "Desde el tímpano hacia dentro" 6) se ejecuta, ya sea al seguir la lectura en la pantalla o sosteniéndola en las manos, pero siempre manipulando estas formas.

\section{SOBRE EL SOPORTE DIGITAL: LA MAQUINITA DE AZAR EN SUS REITERACIONES}

Para Katherine Hayles, la literatura electrónica es un "monstruo esperanzador" (4) compuesto de partes que provienen de distintas tradiciones. Un texto digital sería, entonces, un híbrido por naturaleza, en el que se negocian $\mathrm{y}$ se unen distintos vocabularios y expectativas. El texto que analizo se podría enmarcar dentro de la literatura en formato digital: "aquella literatura concebida en un formato digital para ser leída en la pantalla de un dispositivo electrónico interactivo" (Gainza, Narrativas 20). A veces cubierto por las aguas es una serie de poemas para ser leídos en la pantalla de un computador. Se encuentran en la web Poesía Cero, que presenta un formato neutro, un fondo blanco con los títulos de los poemas en letras negras y algunos títulos en color verde. Cuando se clickea en el título $A$ veces cubierto por las aguas se abre una descripción técnica (a la manera de una página legal) y una advertencia: 


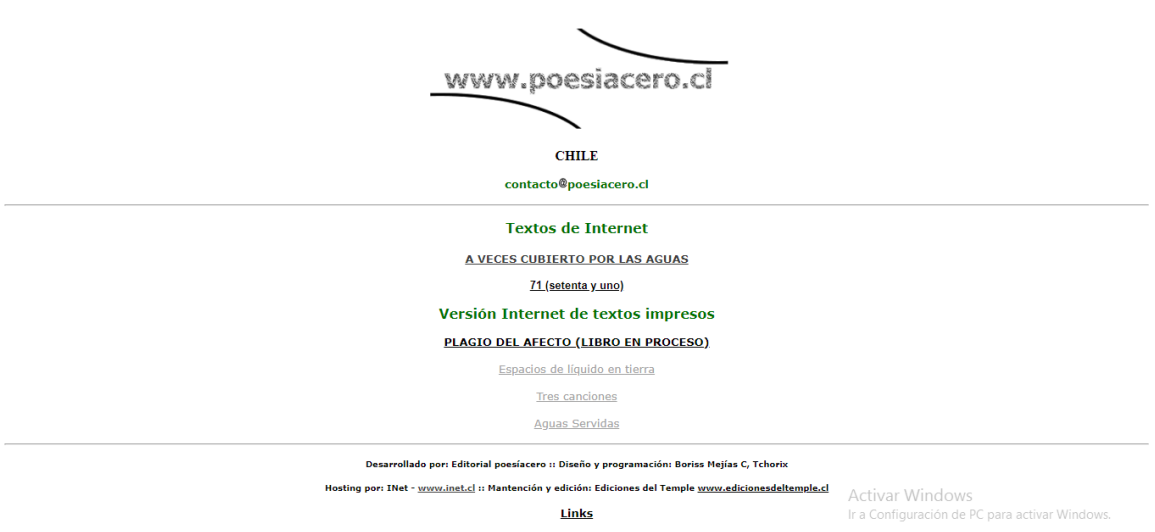

Figura 1. Captura de imagen del sitio web Poesía Cero

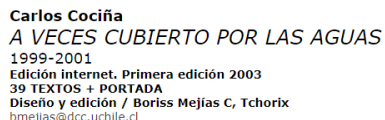

IMPORTANTE Motor de búsqueda aleatorio en el cual el usuario accede a uno de los 39 poemas cada vez. Al desear ver otro poema, se despliega nuevamente al azar uno de los 39, pudiendo repetirse un poema visto anterlormente. Existe la opción de regresar, pero la elecclón de otro poema, será slempre aleatorio.

Desarrollado con PHP

\section{COMENZAR}

Editorial poesíacero wwww.poesiacero.cl

Registro de Propiedad Intelectual. Inscripción número 123868 de 2 de enero de 2002

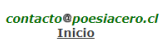

FiguRA 2. Captura de imagen online de $A$ veces cubierto por las aguas

Apenas ingresamos al sitio, se nos ofrece un manual de uso. Es importante conocer el funcionamiento de la obra, saber que son textos por explorar, sin destinos. Cuando se entra al poema, se presenta un bloque que contiene dos botones en las esquinas para ser operados por el lector: "Inicio" y "Otro". 
El diseño de la web facilita la exploración de los poemas. El significado potencial, a partir del lenguaje codificado que es un recurso combinatorio, se construye a medida que el lector cliquea, a medida que se pulsa "Otro", porque el botón "Inicio" nos lleva de vuelta al listado de los títulos de Cociña.

Otro

Los puentes son nada menos que eso. En un real precipicio tienden una obra de arte sobre la cual se puede

Figura 3. Captura de imagen online de uno de los textos de $A$ veces cubierto por las aguas

Esta "maquinita de azar" - o "máquina de producción de una variedad de expresiones", si seguimos a Espen Aarseth (3)-caracteriza a alguien que hizo los textos especialmente para la web y dirigidos a un lector que funciona como un operador activo y se convierte en "un jugador, un apostador" (Aarseth 4). Visto como un cybertext, en $A$ veces cubierto por las aguas el lector puede explorar, perderse, aburrirse e incluso descubrir zonas secretas, porque, según Gainza, de otra manera, la textualidad y poética no se desplegarían, la máquina no funcionaría y el significado no se produciría (Narrativas 76).

Por otro lado, me gustaría sugerir que esta escritura es una escritura abierta, no exclusiva del espacio de la literatura, que idea nuevas formas y es comparable a lo que comenta Juan Luis Martínez en torno a cómo se interviene la idea de libro: "Creo que los libros son fragmentos de un solo libro [...] Yo sostengo que la desintegración de las formas no es inagotable" (100). A diferencia de un libro de poesía normal, con un orden estético y textual establecido por las páginas -al igual que en La nueva novela (1977) o El poeta anónimo (2012)-, el motor de búsqueda es producto de la potencialidad y las restricciones. Las combinaciones de los textos tienden al infinito, están en movimiento y resultan múltiples. Carolina Gainza confirma la óptica del juego en los textos electrónicos, por lo que el lector "activa un deseo de intervención [y] de manipulación" ("Literatura chilena" 247). Aquí el lector y los poemas son afectados por la materialidad de la obra y la posibilidad de operar en una interacción bajo una serie de textualidades.

En particular, pienso que $A$ veces cubierto por las aguas está cercano a Composición $n^{\circ} 1$, de Marc Saporta, una obra de 1962 compuesta de hojas 
sueltas e impresas por un solo lado, dispuestas al azar en una caja, que deben ser revueltas por el lector. En 2011 se realizó una versión para iPad, donde el dispositivo origina el orden aleatorio, por lo que este sería el camino de publicación revertido del recorrido de los poemas de Cociña. A veces cubierto por las aguas -al igual que Composición $n^{\circ} 1-$, cada vez que se lee, está a la espera de construirse. No hay obra definitiva aunque exista en la web o en soporte impreso, la coherencia es la combinatoria y la posibilidad maleable de estos bloques textuales. El lenguaje de los códigos se aproxima a lo que cree Gainza, a esta performatividad del hipertexto atada al deseo de manipulación e intervención del lector.

El 18 de mayo hice una lectura de $A$ veces cubierto por las aguas. La lectura fue aleatoria, por lo tanto para llegar a leer los 39 textos hubo una repetición constante entre sí. Dos fueron los que más se reiteraron, este por lo menos siete veces:

Las edificaciones barrocas y todo lo construido es de color terracota, como lo son las ciudades meridionales, sin embargo el puente Carlos Praga tiene forma gris para despistar al enemigo. Aún así, se construyen piñas de pino de cristal para alcanzar eternidades. Esas mismas, como un corazón de espejo, se opacan ante el neohueso formado en torno a las barras de titanio (párr.1).

El segundo texto que tuvo más recurrencia-conté 6 veces-fue el siguiente:

La vaginal Eloísa descubre que la distancia entre dos estrellas es imaginaria y olvida el asco al calor, cuando siente que el que considera el río más profundo está en su casa. Libre y en salud, cierra los ojos y es dueña del éxtasis que le revela los dioses (párr.1).

En los textos no es claro que exista una apropiación de elementos pertenecientes a otras obras, como sí ocurre en Plagio del afecto, en el que Cociña plagia, interviene y comenta textos no-literarios. Para contrastar, en la versión web del libro hay saltos entre el afecto 6 y el 15, y del 19 al 33. En la impresa, esos vacíos se transforman en páginas en blanco, quizá, como piensa Carolina Gainza, "invitando al lector a que incluya sus propios textos, distorsiones y plagios" ("Pantalla", párr. 4). Tal como en A veces cubierto por las aguas, el lector es invitado a continuar una obra en continuo proceso de creación y transformación, solo que aquí ocurre una reiteración de los bloques 
textuales. La lectura aleatoria permite que el procedimiento de la reiteración no sea una simple rima o una aliteración, sino que es crucial para vincular esta práctica con un contexto que reside en el trabajo con las tecnologías digitales. El sentido, en este soporte en lenguaje codificado y digital, no se construye a partir de la linealidad de las series del texto, como podría suceder en un libro común y corriente. Se produce un montaje serial que apunta a un desgaste, donde la acumulación es una cualidad que produce, siguiendo los procedimientos oulipianos, un significado potencial.

La reiteración en $A$ veces cubierto por las aguas no es una figura retórica. Felipe Cussen plantea que este tipo de trabajos experimentales han sido procesados y convertidos en códigos digitales ("Para una poética" 45), y son susceptibles de ser manipulados mediante algoritmos, combinados modularmente, recodificados y reprogramados. Este es el primer aspecto que sobresale en las secuencias del texto, porque trata de modularse en torno al azar y a la potencialidad que le da el motor de búsqueda creado con tecnologías y códigos digitales. Siguiendo la lectura de Gainza, aquí son el control y lo hipertextual quienes determinan la lectura del poema, pues el conjunto está construido a partir de enlaces electrónicos (Narrativas 69). Bajo esa mirada, los roles del autor y del lector se transforman. El lector toma un rol activo, crea su propio camino de lectura y pasa a ser un operador.

Para Marjorie Perloff el lector "se asemeja a un programador quien conceptualiza, construye, ejecuta y mantiene una máquina de escritura con gran destreza" (cit. en Goldsmith 11). Esta definición es cercana a la definición de un cybertext por parte de Espen Aarseth, que corresponde a ver el texto como una máquina (21), un proceso y una secuencia semiótica, un movimiento que conforma una secuencia física, una máquina que produce expresiones (1). En rigor, es la potencialidad del lenguaje de códigos lo que da existencia a la literatura digital. Esta visión se completa al pensar el texto tanto como un medio material y como una colección de palabras; es decir, la máquina textual no estará completa sin un tercero, sin un operador (Aarseth 21). La tríada medio, textualidades y lectores-operadores, en definitiva, se encuentra en negociación por el significado, en donde ninguno ocupa una posición pasiva.

De igual modo, en Cociña el control y lo hipertextual son aspectos clave que dan cuenta de una poética que establece un pacto con el lector, a quien se ofrece el poema como un motor de búsqueda en el que hay reglas que seguir, un manual. El lector se vincula con la capacidad que brinda el algoritmo, es decir, la capacidad de seleccionar, combinar e incluso alterar esos fragmentos. 
En mi lectura, lo que hice fue copiar y pegar los poemas en un archivo Word, evidenciar un registro, una cadena que pudiera contabilizar las reiteraciones del poema. Mi afán era hacer algo completo, ritualizando incluso la tarea a pesar de la aleatoriedad fría, y conseguir la lectura de esos 39 bloques textuales a pesar del posible agobio y las ganas de pasar a otras pestañas de Internet. Sin embargo, mi lectura tuvo resultados, como la contabilización de repeticiones y, por más que haya podido dar con ellos en su variedad, el corpus final de lectura no fueron 39, sino 92 textos.

Los factores de legibilidad, claridad y limpieza, no solo del lenguaje de Cociña, sino también de la web, llevan a que $A$ veces cubierto por las aguas se configure como una máquina de hacer arte. El escritor y el lector funcionan como programadores y, en cierto modo, la huella autoral se disipa, pues la diagramación y el diseño del motor de búsqueda aleatorio estuvieron a cargo de un ingeniero. Esta distancia se construye a partir de una escritura que se propone en otro método de circulación y distribución y también otro método de recepción y lectura: "el espacio digital fomenta habilidades nuevas que incluyen la 'manipulación' y la 'administración' de masas de lenguaje ya existente y en vías de crecimiento" (Goldsmith 29). A veces cubierto por las aguas, además de generar una acumulación de textos y leer reiteraciones, es capaz de ser un proyecto maleable en sus soportes, materialmente significativo por su neutralidad y fluidez.

\section{"NO NOS HEMOS ALEJADO MÁS ALLÁ DE DOS PASOS O BRAZADAS": EL SOPORTE FÍSICO}

Carolina Gainza advierte que las textualidades digitales, cuando son trasladadas al formato impreso, "pierden su potencial significador" al estar ya rotos sus hipervínculos, al volver estáticas las imágenes y al plegarse "sobre la planilla lineal del texto impreso y la paginación secuencial del libro" (Narrativas 20). Sin embargo, el proyecto de Carlos Cociña sobrevuela esa advertencia, la resignifica y extiende los circuitos de circulación y distribución.

En El margen de la propia vida (2013), la antología de la obra poética de Cociña, se incluye $A$ veces cubierto por las aguas con cada uno de los textos impresos en páginas sueltas dentro de un sobre. La antología es un libro de la colección "Calles de mano única" del sello Alquimia ediciones, de $23 \times 17$ centímetros, en el que se utiliza la tipografía Adobe Garamond Pro. Las páginas sueltas, los 39 bloques textuales, aparecen en hojas blancas que 
miden $13,3 \times 18,6$ centímetros. Los textos llevan a un costado izquierdo el nombre del autor, el título y el logo de la editorial. La solapa cubre al sobre que viene pegado, de forma vertical, a la cara interna de la contraportada.

\footnotetext{
Es lejos donde el río se hace río. En su constitución, el movimiento es secreto. A pesar de ello, el agua llega a este paraje. Las cosas y los momentos surgen de acuerdo a una lógica que pronto se diluye. Basta aplicar el mismo curso a cosas o momentos distintos para reproducir otras corrientes de afecto. Ahí los esquemas se expanden en direcciones imposibles, o sus vectores se ubican al unísono en distintos lugares. Momentos inimaginables cuyo único trazo es la descarga. Cosas de luminosidad incontenible, que sólo se dirige a sí misma. Pero casi siempre las aguas forman un curso, cuyo origen está en cualquier momento de las cosas.
}

FiguRA 4. Una de las hojas sueltas de $A$ veces cubierto por las aguas

Este soporte da una forma física al texto que habíamos leído digitalmente. La lectura aleatoria se mantiene y se logra con mayor libertad, sin reiteraciones, liberada del manual de uso del motor de búsqueda. Llegando al final del libro, tras el índice-donde $A$ veces cubierto por las aguas no aparece-, junto al colofón, se encuentra el sobre blanco, sin ninguna indicación, solo con el peso de los 39 poemas. Al tomar los textos -desparramarlos, arrumbarlos, moverlos- el libro pierde peso y estos, sin pegado ni cosido, se tornan frágiles, dan señas de una forma portátil y móvil de lectura que viene dada por el soporte y lo aleatorio.

Otro aspecto que se mantiene es la manipulación e intervención consciente que los lectores queremos hacer con los textos. La lectura y el motor de búsqueda se hacen palpables, la navegación y la ruta fluctúan en las manos al igual que The Unfortunates (1969), de B. S. Johnson: textos publicados en una caja con 27 cuadernillos irregulares, sin encuadernar, donde solo los capítulos "First" y "Last" aparecen designados como tales, mientras que los 25 intermedios deben leerse en el orden que elijamos. La forma del libro buscaba la naturaleza aleatoria de la mente y la falta de estructura de la memoria. Ambos 
textos, sobre todo $A$ veces cubierto por las aguas, se sostienen sin orden, se permiten agarrar y manipular. Si revisamos la etimología de manipular, llegamos a "mano", que proviene del latín manus. Corominas observa que "mano" puede referirse al "lance en un juego" (820), es decir, a las jugadas, las pasadas, el arrojo de una ocasión, o también al acto de maniobrar, con toda la operación del "trabajo con la mano" y, en definitiva, al manejo y maniobra del puñado. Podría ser que el conjunto sea un puñado manejable, pero creo, como Cussen, que el carácter fragmentario de los textos opera, a pesar de la manipulación, "excéntricamente, disparando para distintos lados" ("Presentación aleatoria" párr. 15).

En mi lectura, saqué cinco bloques textuales al azar. Fue extraño que uno de ellos me recalcara el ejercicio casual, pero incluso revelándose allí: "Es éste un acto desde el azar" (s/n). Todo el proceso, más allá del trasvasije del soporte, invita al lector a intervenir ahora esparciendo los poemas, casi desafiándolo a que participe en este objeto volátil y hasta frágil, unido por la mirada exhaustiva que recorre territorios desplazados, islas, orillas, torrentes y aguas: "Es posible hacer otras orillas donde los sonidos tienen velocidad infinita entre la ausencia y lo imperceptible" (s/n).

Hay una búsqueda en la escritura de Cociña, un intento por hallar en el poema la acción de un exterior sobre un interior y viceversa, o indagar en los límites de los paisajes y sentidos trenzados con la percepción:

Hemos estado aquí desde la época en que las aguas dejaron un olor a sábanas de principios de siglo. Deslizo el vehículo sin mayor problema y el viento de la ciudad hace llover no la lluvia sino el aire sobre la superficie. No hay dolor sino la percepción de que algo se quiebra $(\mathrm{s} / \mathrm{n})$.

Y una percepción precisa, tan rigurosa como en la última frase del texto citado. De hecho, la posibilidad constructiva y metafórica que Cociña plantea, como en Espacios de líquido en tierra -libro también incluido en la antología- se da en las islas, en estos espacios - a veces- rodeados de agua. Así, los afluentes se esparcen, la lluvia hace resbalar el recorrido de las formas, se despliega un espacio habitable de superficies porosas, cargado en las manos, que se compagina y descompagina, marca una ruta, patente aun en uno de los textos que produce observaciones sobre el recorrido. Comienza: "Los recorridos son distintos, pero el último tramo es el mismo", y termina: "Todos los recorridos pueden ser los mismos, el tramo final distinto" (s/n). 
El estado físico de los poemas a veces no permite avanzar, pareciera que nos encontramos inmóviles, pero en ningún caso la lectura es trivial. El rigor perceptivo de la mirada de Cociña aquieta, cuando se esgrime la navegación y en la ruta todo se impersonaliza: "Es un espejismo salir a navegar cuando efectivamente no nos hemos alejado más allá de dos pasos o brazadas" $(\mathrm{s} / \mathrm{n})$. Desde esa zona blanca y limpia, cada texto disparado se extiende hacia un término que no tuvo origen más que en la fragilidad del sobre, palabras cambiantes, desvanecidas y evaporadas, quizá el inicio en la lectura digital, esas reiteraciones que se emplazaban de forma reticular y neutra en la pantalla del computador.

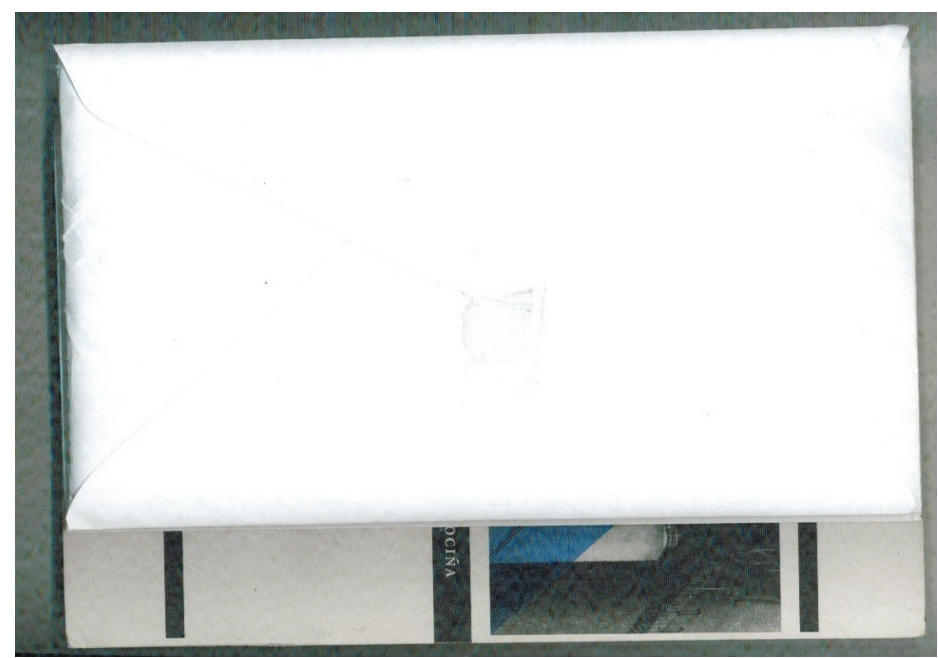

FiguRA 5. El sobre que contiene las hojas de $A$ veces cubierto por las aguas

Sin timbres ni estampillas, el sobre queda instalado en la última zona del libro y marca un recorrido que lo contuvo desde el sitio Poesía Cero. El sobre contiene y es para ser entregado en las manos. Ese método puede relacionarse con las prácticas del mail art o tener vinculación con el interés en torno a los medios de comunicación. Y sí, la referencia a un medio se mantiene, el Internet y el sobre lo son, determinan esa forma. En todo caso, creo que el sobre adherido a la contratapa indica una transmisión frágil, que podría dejar de contenerse allí, sufrir de pronto un accidente. 
Graciela Speranza concibió el libro Atlas portátil de América Latina (2012) pensando en las formas errantes y en los artefactos móviles de la literatura y el arte latinoamericano del siglo xxi. El libro ofrece un atlas diverso de imágenes, textos, obras y fragmentos de ficciones, se define portátil y busca en el arte latinoamericano formas que desdibujan tanto fronteras geopolíticas como límites de lenguajes y medios. La lectura de Speranza guía y presenta obras que muestran una imaginación potencial, y lee estas obras como una interfaz que modifica lo visible, las formas de percibir y expresar los sucesos artísticos. Creo que la obra de Cociña podría ingresar a este programa, pues tanto el soporte digital y el impreso señalan una ruta de formas errantes para enfrentarse a la obra. Una idea lábil del conjunto, significativa por su liviandad, donde el soporte se vuelve versátil, vaga y deambula.

Que $A$ veces cubierto por las aguas ofrezca este flujo está posibilitado por la neutralidad de la obra. La forma, como dice Ian Burn, es la más neutra, no dificulta ni siquiera la información, sino que la extiende. Así, las prácticas experimentales de desmaterialización refieren al abandono de los formatos tradicionales, que desplazan el interés del objeto hacia los procesos de escritura y a los tipos de experiencia desarrollados en los diversos dispositivos y soportes.

\section{EL TRASVASIJE DE LAS AGUAS EN LA LECTURA CON LA ORQUESTA DE POETAS}

A veces cubierto por las aguas ocupa soportes que desdibujan las fronteras de los medios y crean espacios híbridos, desarraigados, a la marcha de un intento por insistir en artefactos que se articulan de otro modo. Esto se confirma, incluso, en un tercer desplazamiento del soporte, que corresponde a la lectura del texto por el propio Carlos Cociña y la Orquesta de Poetas. La versión, que vi en YouTube, está organizada desde la proyección de los textos a una pantalla, a medida que el motor de búsqueda aleatorio funciona. En el registro de la lectura, además, podemos ver a Federico Eisner y a Fernando Pérez moviendo agua de un bol, la que luego trasvasijan en jarros, hacen gárgaras, brindan y hacen sonar copas. A esto lo acompaña un contrabajista y el proceso de deformación de la voz, realizado por Felipe Cussen con un plug-in, contrasta con la neutralidad y el tono descriptivo de los textos.

La representación de esta performance confirma que Cociña es un poeta versátil y que, con la misma fluctuación y condensación del lenguaje, deambula entre los medios sin problemas, más bien porque las restricciones 
que operan en los distintos soportes funcionan. Esto me lleva a reflexionar sobre uno de los primeros asuntos que planteé en el artículo: el cambio de estado físico del lenguaje, la poesía es una forma de evaporación, de alterar el lenguaje, como señala Mario Montalbetti. Todas las referencias al agua señalizan esos estados, los movimientos líquidos del poema, como evidencia el propio Cociña:

Algo pasa con la observación del agua sobre el agua. Sentado al lado dijo que el día de ayer llovieron todas las hojas del otoño. No hubo viento ni cambios bruscos de temperatura. Es la piel la que acaricia la mano ( $A$ veces $\mathrm{s} / \mathrm{n})$.

El poema anuncia una "observación" de estados. Se miran las hojas, se estudia la temperatura como hecho físico y, de este modo, se configura un procedimiento certero que guía los trasvasijes de los textos que he analizado. Si hablamos de trasvasar soportes, entonces, en la versión de la Orquesta de Poetas, esa ruta se señala en los movimientos del agua, en la deformación y ampliación de la voz, en las notas largas y tensas del contrabajo.

En todo este juego experimental con la condensación del lenguaje y del agua hay un arco tendido con las exploraciones que hacía John Cage. En particular, si nos remitimos a Water Walk ${ }^{8}$, su performance realizada en televisión en 1960. En la composición, que dura tres minutos, los instrumentos están relacionados con el agua: una olla a presión en funcionamiento, un patito de hule, una trituradora de hielo, una regadera de flores, una botella de vino, una tina y un sifón. Cage controla el tiempo de los eventos con un cronómetro, se pasea entre los elementos, a veces da golpes al piano -el único instrumento tradicional- o arroja al suelo algunas de las radios portátiles que también intervienen en la obra.

El asunto, además de los sonidos que se generan, radica entre las acciones -medidas, en orden, como si la partitura fuera un conjuntos de restriccionesy el agua. El elemento se presenta en estado líquido, gaseoso y sólido, incluso como potenciador de sonidos. En efecto, hay un silbato en la jarra que produce resonancias, por lo que se amplifican las formas tradicionales

8 Un registro de la presentación de la obra en el programa de televisión I've Got a Secret, en enero de 1960, está disponible en el siguiente enlace: https://www.youtube.com/ watch?v=gXOIkT1-QWY 
de interpretar la música, o la importancia del movimiento del propio Cage al trasvasar los elementos, al producir un paseo acuático -similar a ciertas acciones y elementos que usa la Orquesta de Poetas en la lectura de Cociña-. Así, el agua es un material que, a pesar de lo común y mínimo que puede ser, potencia una manera de hacer música. De ahí que Cage, en la misma entrevista previa a la acción, se defina como músico experimental y, ante la pregunta del presentador del programa sobre por qué consideraría música lo que se exhibiría, ponga el foco en la producción y en los actos que luego lleva a cabo.

El trasvasije de las aguas de Cage y de la Orquesta de Poetas grafica que un poema es un cambio de estado del lenguaje, una alteración. Hay medios, como la concatenación de movimientos en las acciones vistas, que señalan estas evaporaciones. Que Cage, con la misma performance, altere la música usando agua, o que Cociña utilice distintos soportes con un lenguaje frío e impersonal, indican que hay un estado por trasvasijar, intervenciones que hacer y afectar en el flujo natural del lenguaje. El agua, en definitiva, nos permitiría acceder a otro lenguaje que, como materia, nos propone entrar en un lenguaje extendido, en una potencialidad en estado líquido, gaseoso o sólido.

\section{CONCLUSIONES}

En mi última lectura de $A$ veces cubierto por las aguas, hecha en la web, el texto que más repeticiones tuvo fue este:

Los puentes son nada menos que eso. En un real precipicio tienden una obra de arte sobre la cual se puede transitar y trasladarse a otra isla. El lugar donde se va es parecido. La luz está en el otro lado y es el mismo ( $\mathrm{s} / \mathrm{n})$.

Quizá estos textos, pensados para ser leídos en Internet, no para un libro normal de poesía, sean puentes. No sé si los lugares son parecidos, pero sí mantienen aspectos comunes, como los efectos de la navegación y una idea abierta y liviana del soporte que tensiona la noción de libro. A propósito, Ulises Carrión propone la autonomía del libro frente a los textos, su suficiencia por sí misma, pero tampoco descarta que persista una escritura que acentúe y se integre a la forma nueva del soporte. Una de las máximas de Carrión es que el escritor ya no se dedica a escribir, sino que "en el arte nuevo el escritor 
hace libros" (39). Las páginas de un libro tienen funciones particulares, no son iguales, se ofrecen a la realidad, se palpan, señalan vías de intercambio y de utilización. Si hay un puente entre esta propuesta y la de Cociña, es en el vínculo por captar el libro en tanto estructura, deteniéndose y leyendo las funciones que lo determinan, asumiéndolas con libertad en sus usos y dispositivos.

Así, A veces cubierto por las aguas enfrenta las maneras de publicación y circulación estableciendo un vínculo con la desmaterialización de los soportes. Fuera de la página y del verso, con su potencialidad aleatoria, se inmiscuye dentro de un estilo impersonal y en un marco experimental frente a la obra que pone el foco en los procesos mentales y en la ejecución distanciada. Al trabajar con los procedimientos escriturales de potencialidad y restricción, se establece un nexo con la textualidad digital, que permite crear obras originales a partir la aleatoriedad y las estructuras provenientes de la programación. El poema de Cociña aborda e incorpora los códigos que generan lenguaje en las interfaces de la red para emplearlos, al mismo tiempo, como una potencialidad y una restricción, que pueden ser leídos al alero de los Critical Code Studies propuestos por Mark Marino'.

Por otro lado, el trabajo con la potencialidad y la restricción ofrece una lectura ligada a la alteración física de los soportes. En último término, el proyecto de Cociña se pliega dentro de lo que María Giovine plantea bajo la óptica de una "poesía y escritura perceptual" (2). En lugar de restringirse a trabajar en un plano visual, esta estrategia apunta a una experiencia de percepción completa e integral, caracterizada por circular en soportes alternativos, donde "los poemas perceptuales se mueven y cambian, es decir, son transitorios, fugaces y, al ser obras muy abiertas, requieren de la participación activa del perceptor para la configuración de sentido" (ibid.). Como ocurre en $A$ veces cubierto por las aguas, en estas poéticas el libro no se utiliza en su sentido habitual, sino que, por el contrario, resulta clave el énfasis en la percepción e interacción de lo textual y los soportes, al igual que el uso de mecanismos y acciones que varían lo prototípico de un libro y su escritura.

\footnotetext{
Mark Marino propone no seguir hablando del "código como un texto en términos metafóricos", sino analizarlo y explicarlo como un texto, "como un sistema de signos con su propia retórica y como una comunicación verbal cuya significancia excede a su utilidad funcional" (4).
} 
Para $A$ veces cubierto por las aguas, el término poesía perceptual sirve para indicar un camino de conceptualización de estas prácticas con el trabajo de los poemas, que sucede en todos sus soportes y se pregunta por la manera en que leemos. En estos nuevos formatos de escritura, la textura es una tecnología que se llena en la pantalla,. La experimentación opera como una nueva red y una nueva manera de leer y ubicar la escritura de hoy y del futuro. Entonces, se diagraman y se piensan los nuevos modos de practicar programaciones, nuevos sentidos que la escritura potencia. En definitiva, hay un cambio de paradigma que juega con los hipervínculos y un sistema estético complejo: la manipulación poética de reglas lingüísticas, signos y letras para producir modelos de lectura que disparan para todos lados.

\section{BIBLIOGRAFÍA}

Aarseth, Espen. Cybertext. Perspectives on Ergodic Literature. Baltimore, The Jhons Hopkins University Press, 1997.

Alemian, Ezequiel y Malena Rey (eds.). Oulipo: Ejercicios de literatura potencial. Buenos Aires, Caja Negra, 2016.

Ayala, Matías. "Lo impersonal: notas sobre la poesía de Carlos Cociña". Academia.edu (web), junio de 2014, consultado el 21 de noviembre de 2021, disponible en: https://www. academia.edu/7586469/Lo_impersonal_notas_sobre_la_poes\%C3\%ADa_de_Carlos Coci\%C3\%B1a_2014_

"Dictadura, transición y reescritura en Gonzalo Millán”. Chasqui. Revista de literatura latinoamericana XXXIX, $\mathrm{N}^{\circ} 1,2010$, pp. 64-80.

Barthes, Roland. “La muerte del autor”. El susurro del lenguaje. Barcelona, Paidós, 1987, pp. 65-72.

CAGe, John. Water Walk, 1960. YouTube (web), holotone, consultado el 21 de noviembre de 2021, disponible en:

https://www.youtube.com/watch?v=SSulycqZH-U

CArrión, Ulises. El arte nuevo de hacer libros. Ciudad de México, Tumbona, 2012.

Claro, Andrés. Imágenes de mundo. Santiago, Ediciones Bastante, 2016.

Cociña, Carlos. "A veces cubierto por las aguas". Poesía Cero (web), 2003, consultado el 21 de noviembre de 2021, disponible en: <http://www.poesiacero.cl/>.

Plagio del afecto. Santiago, Ediciones Tácitas, 2009.

Plagio del afecto. Poesía Cero. Libro en proceso 2003-2005. Web, consultado el 21 de noviembre de 2021, disponible en:

http://poesiacero.cl/plagiodelafecto.html 
"Desde el tímpano hacia dentro". Entrevista realizada por Felipe Cussen. Revista Chilena de Literatura 77, sección Miscelánea virtual (web), 2010, consultado el 21 de noviembre de 2021, disponible en:

https://revistaliteratura.uchile.cl/index.php/RCL/article/view/9050

El margen de la propia vida. Santiago, Alquimia ediciones, 2013.

CoRominas, JoAn. Diccionario crítico etimológico castellano e hispánico. Madrid, Gredos, 1980.

Cussen, Felipe. "Para una poética de la repetición". Meridional. Revista chilena de Estudios Latinoamericanos 5, 2015, pp. 41-58.

"Presentación aleatoria de El margen de la propia vida de Carlos Cociña". Paniko. $c l$ (web), 2013, consultado el 21 de noviembre de 2021, disponible en: https://paniko.cl/ presentacion-aleatoria-de-el-margen-de-la-propia-vida-de-carlos-cocina/

Cruz, Roberto. "Dispositivos artísticos post-digitales: escrituras de ida y vuelta". Red Humanidades Digitales (web), 18 de abril de 2014, consultado el 21 de noviembre de 2021, disponible en: http://humanidadesdigitales.net/dispositivos-artisticos-post-digitalesescrituras-de-ida-y-vuelta/

Gainza, CARolina. "Literatura chilena en digital: mapas, estéticas y conceptualizaciones". Revista Chilena de Literatura 94, 2016, pp. 233-256.

"Pantalla y Papel: Materialidad Digital y Materialidad Análoga en Plagio del afecto de Carlos Cociña”. Centro de Cultura Digital (web), 10 de diciembre de 2015, consultado el 21 de noviembre de 2021, disponible en: http://editorial.centroculturadigital.mx/articulo/ hackear-la-cultura-poeticas-del-plagio-en-la-poesia-de-carlos-cocina

Narrativas y poéticas digitales en América Latina. Santiago de Chile, Cuarto Propio, 2018.

Giovine, MaríA. "Poesía perceptual: experiencias poéticas interactivas". Revista Laboratorio 9, (web), 2013, consultado el 21 de noviembre de 2021, disponible en: https://revistalaboratorio. udp.cl/index.php/laboratorio/article/view/172/165

Goldsmith, Kenneth. Escritura no-creativa: la gestión del lenguaje en la era digital Ciudad de México, Tumbona y Sur ediciones, 2015.

Hayles, Katherine. Electronic Literature. New horizons for the literary. Indiana, University of Notre Dame, 2008.

Howsam, Leslie. Old Books and New Histories: An Orientation to Studies in Book and Print Culture. Toronto, University of Toronto Press, 2006.

Illich, Ivan. En el viñedo del texto. Etología de la lectura: un comentario al "Didascalicon" de Hugo de San Victor. Ciudad de México, Fondo de Cultura Económica, 2002.

Johnson, B. S. The Unfortunates. Londres, Pan Macmillan, 1999.

Le Lionnais, François. "La LIPO (Primer Manifiesto)". ElHablador 9 (web), septiembre de 2005, consultado el 21 de noviembre de 2021, disponible en: https://www.elhablador. com/patafisica3.htm

Lescure, JeAn. "Breve historia del Oulipo". Ideas potentes: atlas de literatura potencial, 1. OULIPO. Logroño, Pepitas de calabaza, 2016, pp. 33-44.

LipPaRD, LuCy R. Seis años: la desmaterialización del objeto artístico de 1966 a 1972. Madrid, Ediciones Akal, 2004. 
Marino, Mark. "Critical Code Studies". Electronic Book Review (web), 12 de abril de 2006, consultado el 21 de noviembre de 2021, disponible en: https://electronicbookreview.com/ essay/critical-code-studies/

Martínez, Juan Luis. Poemas del otro. Santiago, Editorial Universidad Diego Portales, 2003.

Millán, Gonzalo. La poesía no es personal. Santiago, Alquimia ediciones, 2012.

Montalbetti, Mario. "Si todo el verde de la primavera fuera azul... (Sobre necesidad y contingencia en el poema)... y lo es". Revista Estudios Avanzados 26, 2016, pp. 157-166.

Orquesta de Poetas. "La Orquesta". Orquestadepoetas.cl (web), consultado el 21 de noviembre de 2021, disponible en: < https://www.orquestadepoetas.cl/la-orquesta $>$.

"Orquesta de Poetas \& Carlos Cociña”. Orquestadepoetas.cl (web), consultado el 21 de noviembre de 2021, disponible en:

https://www.youtube.com/watch?v=x31q2ziW388

Real Academia Española. "escribiente". Diccionario de la lengua española (web), consultado el 21 de noviembre de 2021, disponible en: https://dle.rae.es/escribiente

Saporta, Marc. Composición $n^{\circ}$ 1. Madrid, Capitán Swing, 2012.

Speranza, Graciela. Atlas portátil de América Latina. Arte y ficciones errantes. Barcelona, Anagrama, 2012.

VV.AA. Cien mil millones de poemas: homenaje a Raymond Queneau. Madrid, Demipage, 2016. 